\title{
A Rare Case of Left Main Coronary Artery Aneurysm
}

\author{
Iva N. Dimitrova ${ }^{1}$, Georgi Kotov ${ }^{2}$, Alexandar Iliev ${ }^{2}$ \\ 1. Cardiology, St. Ekaterina University Hospital, Medical University of Sofia, Sofia, BGR 2. Anatomy, Histology and \\ Embryology, Medical University of Sofia, Sofia, BGR
}

Corresponding author: Alexandar Iliev, dralexiliev@abv.bg

\begin{abstract}
Coronary artery aneurysms are uncommon and are usually described as dilatations larger than 1.5 times the diameter of the adjacent coronary arteries. The aneurysms vary between $0.15 \%$ and $4.9 \%$ and usually affect the right coronary artery, followed by the circumflex and anterior descending artery. Left main coronary artery (LMCA) aneurysm is an extremely rare clinical entity. Herein, we present a case in a 69-year-old man with a prior history of chest pain and palpitations. Significant ischemic ST changes were registered on Holter electrocardiography during paroxysmal atrial fibrillation.
\end{abstract}

Categories: Cardiology, Radiology, Anatomy

Keywords: coronary artery aneurysm, left main coronary artery

\section{Introduction}

Aneurysms of the coronary arteries are rarely reported in the literature. Their incidence varies between $0.15 \%$ and $4.9 \%$ of patients and they usually affect the right coronary artery, followed by the circumflex and anterior descending artery [1-2]. Left main coronary artery (LMCA) aneurysms are extremely rare and account for approximately $0.1 \%$ of coronary artery aneurysms [3]. Commonly, aneurysms can be divided into saccular or fusiform, single or multiple. Saccular aneurysms are usually spherical with larger transverse diameter, while fusiform ones have a larger longitudinal diameter. The term 'aneurysm' of the coronary artery is used when the dilatation exceeds the diameter of adjacent normal segments or the diameter of the patient's largest coronary vessel by 1.5 times [4]. Although rare, possible complications of coronary aneurysms have been reported. An aneurysm could become spastic, undergo thrombosis and spontaneous dissection and could lead to acute myocardial infarction [3,5].

Herein, we describe a case of a 69 -year-old male presenting with chest oppression and palpitation, whose coronary angiogram revealed the presence of an LMCA aneurysm.

Received 03/04/2019

Review began 03/05/2019 Review ended 03/05/2019 Published 03/06/2019

(c) Copyright 2019

Dimitrova et al. This is an open access article distributed under the terms of the Creative Commons Attribution License CC-BY 3.0., which permits unrestricted use, distribution, and reproduction in any medium, provided the original author and source are credited.

\section{Case Presentation}

A 69-year-old male of Europid origin with risk factors including high blood pressure, dyslipidemia, and diabetes presented to the Clinic of Cardiology at University Hospital St. Ekaterina with symptoms of chest oppression and palpitations. Holter electrocardiography monitoring registered paroxysmal atrial fibrillation with ischemic ST changes. An echocardiography scan showed preserved left ventricular ejection fraction (62\%), low-grade mitral regurgitation, moderate aortic regurgitation and initial dilatation of the ascending aorta.

The patient was planned for invasive diagnostic procedure. The coronary angiogram revealed an aneurysmal dilatation of the trunk of the LMCA with a transverse diameter of $11 \mathrm{~mm}$ (Figures $1 A-1 D$ ). 


\section{Cureus}
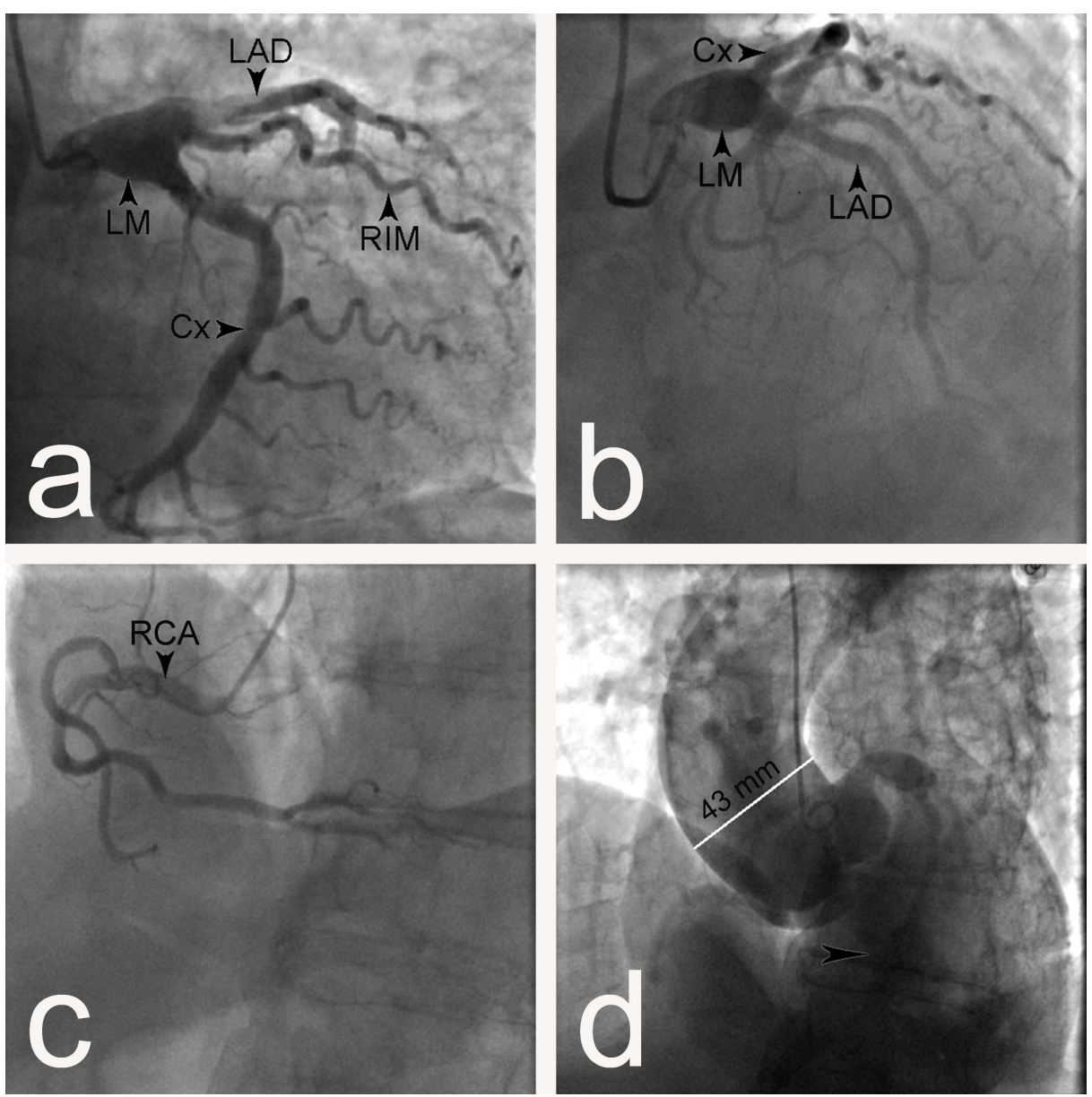

\section{FIGURE 1: Coronary angiogram showing aneurysms of the left main coronary artery and the ascending aorta in a 69-year-old patient}

a, b) Left main coronary artery (LM) trifurcating into the left anterior descending artery (LAD), left circumflex artery (Cx), and ramus intermedius (RIM), a dilatation of the LM is visible; c) Right coronary artery (RCA) without any abnormalities; d) Dilatation of the ascending aorta with a transverse diameter of $43 \mathrm{~mm}$. Arrowhead - aortic regurgitation.

We did not observe stenosis of the coronary arteries due to atherosclerosis. The conducted aortography revealed second-grade aortic regurgitation. The ascending aorta was dilated, with a transverse diameter of $43 \mathrm{~mm}$. The patient was managed non-operatively with medication therapy including a vitamin $\mathrm{K}$ antagonist (acenocoumarol), antiarrhythmic (amiodarone), angiotensin II receptor blocker, $\beta$-blocker and lipidlowering medication (statin).

\section{Discussion}

Literature data on the treatment of LMCA aneurysms are scarcely presented. This could be due to their extremely rare incidence and unpredictable natural history. In a study of 22,000 coronary angiograms, Topaz et al. estimated its frequency to be only $0.1 \%$. The largest width of this aneurysm was $1.9 \mathrm{~cm}$ [6]. Aneurysms have commonly been detected via coronary angiography or intravascular ultrasound and rarely in autopsy [2]. Angiography is the gold standard for diagnosis and treatment, but computed tomography (CT) and magnetic resonance (MR) coronary angiography may help increase detection [2].

The most common cause of coronary aneurysms is atherosclerosis, which accounts for half of the cases reported in adults [2]. Other reasons include congenital malformation, traumatic injury, previous balloon angioplasty, endocarditis, rheumatic fever, mycosis, syphilis, polyarteritis nodosa, systemic lupus erythematosus, Ehlers-Danlos syndrome, scleroderma, Marfan syndrome, Takayasu arteritis, Kawasaki disease, various genetic syndromes and idiopathic [5]. In our case, the aneurysm of the trunk of the LMCA coexisted with a dilatation of the ascending aorta. Thus, we discussed that these multiple aneurysms could be related to an underlying connective tissue disease.

Stabile et al. reported the formation of secondary aneurysms after using drug-eluting stents (DES) [7]. Aneurysmal formation is higher in DES than in bare metal stents (BMS) and may be associated with an 
increased risk for late stent thrombosis [8]. The incidence of aneurysms after DES implantation varies between $0.2 \%$ and $10.5 \%$ [9].

Coronary artery aneurysms are usually asymptomatic. However, the clinical manifestations may vary. A symptomatic coronary artery aneurysm may present with symptoms characteristic for coronary artery disease [10]. Pappy et al. reported that patients could present with symptoms of chest pain (angina pectoris), dyspnea, edema, myocardial infarction, and even sudden death. In our case, the patient presented with chest oppression and palpitations but significant coronary artery disease was not found on the subsequent coronary angiogram [11]. Thus, we discussed that the aneurysm of the LMCA described herein could have provoked the above symptoms.

The treatment of coronary artery aneurysms remains controversial. Different options include medical management, coil embolization, stent placement, and surgery. However, the choice of treatment option depends on the patient condition, concomitant diseases and infections, etiology, location, size and duration in time $[2,12]$. In our case, it was decided that the patient should be treated non-operatively and was managed with a medical therapy, including a vitamin $\mathrm{K}$ antagonist (acenocoumarol), antiarrhythmic (amiodarone), angiotensin II receptor blocker, $\beta$-blocker and lipid-lowering medication (statin).

\section{Conclusions}

Coronary artery aneurysms are rare and commonly represent an accidental finding during coronary angiography. The proper therapy for these patients is not well established and certain controversies exists. In the present case, we reported a rare pathology, which was discussed to have been related to an underlying connective tissue disease, such as Kawasaki disease.

\section{Additional Information \\ Disclosures}

Human subjects: Consent was obtained by all participants in this study. Medical Legal Office, the Local Ethics Committee and the Institutional Review Board issued approval none. Conflicts of interest: In compliance with the ICMJE uniform disclosure form, all authors declare the following: Payment/services info: All authors have declared that no financial support was received from any organization for the submitted work. Financial relationships: All authors have declared that they have no financial relationships at present or within the previous three years with any organizations that might have an interest in the submitted work. Other relationships: All authors have declared that there are no other relationships or activities that could appear to have influenced the submitted work.

\section{References}

1. Huang CY, Huang CH, Chen JW, Lin SJ, Liu TM: Atherosclerotic left main coronary artery aneurysm: case reports. Int J Angiol. 2004, 13:89-91. 10.1007/s00547-004-1066-y

2. Doustkami H, Maleki N, Tavosi Z: Left main coronary artery aneurysm. J Tehran Heart Cent. 2016, 11:41-45.

3. Lima B, Verma SK, Lowee JE: Nonsurgical management of left main coronary artery aneurysm . Tex Heart Inst J. 2006, 33:376-379.

4. Williams MJ, Stewart RA: Coronary artery ectasia: local pathology or diffuse disease?. Cathet Cardiovasc Diagn. 1994, 33:116-119. 10.1002/ccd.1810330206

5. Everett JE, Burkhart HM: Coronary artery aneurysm: case report. J Cardiothorac Surg. 2008, 3:1749-1753. 10.1186/1749-8090-3-1

6. Topaz O, DiSciascio G, Cowley MJ, et al.: Angiographic features of left main coronary artery aneurysms . Am J Cardiol. 1991, 67:1139-1142. 10.1016/0002-9149(91)90881-K

7. Stabile E, Escolar E, Weigold G, et al.: Marked malapposition and aneurysm formation after sirolimuseluting coronary stent implantation. Circulation. 2004, 110:e47-e48. 10.1161/01.CIR.0000138684.58183.6E

8. Abergel E, Roguin A: Coronary aneurysm occurring late after drug-eluting stent implantation . ISRN Cardiol. 2011, 2011:367512. 10.5402/2011/367512

9. Zhong X, Li H, Li C, et al.: Clinical outcomes and risk factors of coronary artery aneurysms after successful percutaneous coronary intervention and drug-eluting stent implantation for chronic total occlusions. Int J Cardiol Heart Vessels. 2014, 4:108-115.

10. Tunick PA, Slater J, Kronzon I, Glassman E: Discrete atherosclerotic coronary artery aneurysms: a study of 20 patients. J Am Coll Cardiol. 1990, 15:279-282. 10.1016/S0735-1097(10)80049-X

11. Pappy R, Wayangankar S, Kalapura T, Abu-Fadel MS: Rapidly evolving coronary aneurysm in a patient with rheumatoid arthritis. Cardiol Res Pract. 2011, 2011:659439. 10.4061/2011/659439

12. Aoki J, Kirtane A, Leon MB, Dangas G: Coronary artery aneurysms after drug-eluting stent implantation . JACC Cardiovasc Interv. 2008, 1:14-21. 10.1016/j.jcin.2007.10.004 